www.jmscr.igmpublication.org

Impact Factor 5.244

Index Copernicus Value: 83.27

ISSN (e)-2347-176x ISSN (p) 2455-0450

crossref DOI: _http://dx.doi.org/10.18535/jmscr/v4i10.05

Journal Of Medical Science And Clinical Research

IGM Publication

An Official Publication of IGM Publication

\title{
Impact of Androgenic Alopecia on the Quality of Life in Male Subjects: Results of an Observational Study from Tertiary Care Hospital
}

\author{
Authors \\ Dr Rahul Bade, Dr Deepak Bhosle, Dr Abhijeet Bhagat, Dr Huzaif Shaikh, \\ Dr Asif Sayyed, Dr Alim Shaikh
}

\begin{abstract}
Objective: To evaluate psychological impact and quality of life of androgenic alopecia in male patients. Material and Methods: A prospective observational study was conducted in male subjects between 15 and 60 years with Androgenic Alopecia (AGA) grade I to VII. Quality of life was measured by Hairdex scale. Dermatology Life Quality Index (DLQI) questionnaire was used to measure the impact of skin problem on the life of patients over the last week.

Results: Two hundred subjects (mean age 30.6 years) were enrolled in the study of which $51 \%$ were between 21-30 years of age. Percentage of subjects with middle class, lower class and upper class socioeconomic status were $34.5 \%, 20 \%$ and $34 \%$ respectively. History of stress was observed in $66.5 \%$ subjects. Positive family history of alopecia was given by $51 \%$ subjects. Scalp and hair condition was dry in $9.5 \%$ subjects while hair pull test was positive in $7 \%$ subjects. The Quality of Life subscales results showed subjects $<30$ years to be less affected on symptoms subscale. They had higher scores than subjects with > 30 years for stigmatization, functioning and emotions $(p<0.05)$. However, the younger age group proved to be more self assured ( $p<0.05)$. Dermatology Life Quality Index (DLQI) score differed significantly in subjects with different age groups (; $p<0.05)$ with highest score in subjects $<20$ years of age. The mean DLQI of younger subjects was significantly higher than older subjects $(p<0.05)$. Conclusion: Younger patients are more stigmatized, have poor functioning and emotions stability, but they had more self assuredness. Younger patients seem to retain better Quality of Life despite AGA.

Key words: Andogenetic alopecia, India, male, observational study.
\end{abstract}

\section{Introduction}

Hair loss is a common problem and associated with cosmetic and psychological distress. ${ }^{1}$ Loss of hair can impact person's social life resulting in psychological consequences. Hair loss in men can also cause significant distress, low self-esteem and low self confidence. People with alopecia have higher level of anxiety and depression. Subjects with alopecia also have impaired quality of life. ${ }^{2}$ Because of these problems, people seek treatment options for maintaining existing hairs and regrowing lost hairs. Androgenetic alopecia (AGA) is the most common cause of hair loss in male population. ${ }^{1}$ On one hand, in many cases the results of treatment are unsatisfactory while on the other hand, people have high expectations, hence counselling is very important in these cases. Today, quality of life is being increasingly considered as a part of outcome measure while treating patients of androgenetic alopecia. There 
are not many studies available on the quality of life in males with androgenetic alopecia although psychological aspects of hair loss were studied widely.

\section{Objective}

The objective of this study was to evaluate psychological impact and quality of life of androgenic alopecia in male patients.

\section{Material and Methods}

This prospective observational study was conducted in the dermatology outpatient department of a tertiary care centre of Mumbai. Male subjects between the age of 15 and 60 years with Androgenic Alopecia (AGA) grade I to VII (according to Hamilton-Norwood classification of hair loss) were recruited. Patients with existing psychopathology and any other associated preexisting medical illness were excluded from the study.

After demographic parameters, age of onset, duration of alopecia and details of family history was recorded. Study subjects were classified for their socioeconomic status using Kuppuswamy Classification. ${ }^{3}$ Quality of life was measured by Hairdex scale. ${ }^{4}$ The scale included questions under five categories; emotions, functioning, symptoms, self-assurance and stigmatization. ${ }^{4}$ The responses were graded from 0 to 4 by the subjects according to frequency with which they occur. Dermatology Life Quality Index (DLQI) questionnaire $^{5}$ was used to measure the impact of skin problem on the life of patients over the last week. The DLQI score was measured according to different age groups and difference was compared between age groups. All subjects were recruited after approval from institutional ethics committee and written inform consent.

\section{Statistical Analysis}

Continuous variables are presented as mean $( \pm \mathrm{tSD})$ whereas categorical data are given as number and percentages. Student's T test and Fischer's exact test are applied to evaluate the difference of
Quality of Life related parameters between groups. The p-value of $<0.05$ was considered as significant.

\section{Results}

A total of 200 subjects with mean age of 30.6 $( \pm 8.7)$ years were enrolled in the study. Table 1 shows age distribution of study participants.

Table 1: Age distribution of study subjects

\begin{tabular}{|l|c|}
\hline Age group (years) & $\mathrm{N}(\%)$ \\
\hline$<20$ & $20(10 \%)$ \\
\hline $21-30$ & $102(51 \%)$ \\
\hline $31-40$ & $41(20.5 \%)$ \\
\hline $41-50$ & $32(16 \%)$ \\
\hline$>50$ & $5(2.5 \%)$ \\
\hline
\end{tabular}

Fifty one percent subjects were between 21-30 years of age while $20.5 \%$ were between $31-40$ years. whereas the mean duration of alopecia was $64( \pm 49.3)$ months

Table 2. Distribution of Study Subjects based on socioeconomic status

\begin{tabular}{|l|l|}
\hline Socio-economic class & $\mathrm{N}(\%)$ \\
\hline Middle & $69(34.5 \%)$ \\
\hline Higher & $68(34 \%)$ \\
\hline Lower & $40(20 \%)$ \\
\hline Upper middle & $22(11 \%)$ \\
\hline Lower middle & $1(0.5 \%)$ \\
\hline
\end{tabular}

Distribution of study subjects based on socioeconomic status was done using Kuppuswamy Classification. ${ }^{3}$ A total of $34.5 \%$ subjects belonged to middle class while $20 \%$ and $34 \%$ belonged to lower and upper class respectively (table 2). $57 \%$ subjects were married while $40.5 \%$ were unmarried. Remaining $2.5 \%$ subjects were divorced. On assessing the personal history, history of stress was observed in $66.5 \%$ subjects whereas acne was present in $39.5 \%$ subjects. $30 \%$ subjects were vegetarian whereas $70 \%$ were mixed vegetarian.

Past history was not significant in majority of the study subjects. Only 6\% subjects had history of either diabetes or hypertension whereas $1 \%$ had both diabetes and hypertension. 
Table 3: Distribution of study subjects based on family history

\begin{tabular}{|l|l|}
\hline Socio-economic class & $\mathrm{N}(\%)$ \\
\hline Paternal side & $37(18.5 \%)$ \\
\hline Maternal side & $33(16.5 \%)$ \\
\hline Both & $11(5.5 \%)$ \\
\hline Sibling + paternal/maternal & $14(7 \%)$ \\
\hline Sibling without paternal/maternal & $6(3 \%)$ \\
\hline Children & $1(0.5 \%)$ \\
\hline None & $98(49)$ \\
\hline
\end{tabular}

Positive family history of alopecia was given by $51 \%$ subjects with $18.5 \%$ and $16.5 \%$ from paternal and maternal side respectively (table 3 ).
Table 4: Cutaneous examination

\begin{tabular}{|l|c|c|}
\hline \multicolumn{2}{|l|}{ General Cutaneous Examination } & \multicolumn{1}{l|}{ N (\%) } \\
\hline $\begin{array}{l}\text { Scalp \& Hair } \\
\text { condition }\end{array}$ & Dry & $19(9.5 \%)$ \\
\cline { 2 - 3 } & Normal & $181(90.5 \%)$ \\
\hline \multirow{2}{*}{ Hair Pull test } & Negative & $186(93 \%)$ \\
\cline { 2 - 3 } & Positive & $14(7 \%)$ \\
\hline \multirow{2}{*}{ Other Hairy areas } & Normal & $200(100 \%)$ \\
\cline { 2 - 3 } & Abnormal & 0 \\
\hline
\end{tabular}

Scalp and hair condition was dry in $9.5 \%$ subjects while hair pull test was positive in $7 \%$ subjects. (table 4).

Table 5: Norwood Hamilton Scale

\begin{tabular}{|l|l|l|l|l|l|l|}
\hline \multicolumn{7}{|l|}{ Age groups (years) } \\
\hline $\begin{array}{l}\text { Norwood } \\
\text { Hamilton } \\
\text { Scale }\end{array}$ & $\begin{array}{l}<20 \\
\mathrm{~N}(\%)\end{array}$ & $\begin{array}{l}21-30 \\
\mathrm{~N}(\%)\end{array}$ & $\begin{array}{l}31-40 \\
\mathrm{~N}(\%)\end{array}$ & $\begin{array}{l}41-50 \\
\mathrm{~N}(\%)\end{array}$ & $\begin{array}{l}>50 \\
\mathrm{~N}(\%)\end{array}$ & Total \\
\hline 1 & 6 & 2 & 0 & 0 & 0 & $\begin{array}{l}8 \\
(15 \%)\end{array}$ \\
\hline 2 & $11(50.0 \%)$ & $\begin{array}{l}11 \\
(50.0 \%)\end{array}$ & 0 & 0 & 0 & $22(100.0 \%)$ \\
\hline $2 \mathrm{~A}$ & $3(20.0 \%)$ & $10(66.7 \%)$ & 0 & $2(13.3 \%)$ & 0 & $15(100.0 \%)$ \\
\hline 3 & 0 & $14(77.8 \%)$ & $2(11.1 \%)$ & $2(11.1 \%)$ & 0 & $18(100.0 \%)$ \\
\hline $3 \mathrm{~A}$ & 0 & $19(76.0 \%)$ & $3(12.0 \%)$ & $3(12.0 \%)$ & 0 & $25(100.0 \%)$ \\
\hline $3 \mathrm{~V}$ & 0 & $16(69.6 \%)$ & $6(26.1 \%)$ & $1(4.3 \%)$ & 0 & $23(100.0 \%)$ \\
\hline 4 & 0 & $17(53.1 \%)$ & $\begin{array}{l}11 \\
(34.4 \%)\end{array}$ & $4(12.5 \%)$ & 0 & $32(100.0 \%)$ \\
\hline $4 \mathrm{~A}$ & 0 & $3(23.1 \%)$ & $6(46.2 \%)$ & $2(15.4 \%)$ & $2(15.4 \%)$ & $13(100.0 \%)$ \\
\hline 5 & 0 & $3(25.0 \%)$ & $4(33.3 \%)$ & $5(41.7 \%)$ & 0 & $12(100.0 \%)$ \\
\hline $5 \mathrm{~A}$ & 0 & $5(31.2 \%)$ & $5(31.2 \%)$ & $6(37.5 \%)$ & 0 & $16(100.0 \%)$ \\
\hline 6 & 0 & $2(16.7 \%)$ & $4(33.3 \%)$ & $5(41.7 \%)$ & $1(8.3 \%)$ & $12(100.0 \%)$ \\
\hline 7 & 0 & 0 & 0 & $2(50.0 \%)$ & $2(50.0 \%)$ & $4(100.0 \%)$ \\
\hline Total & $20(10.0 \%)$ & $\begin{array}{l}102 \\
(51.0 \%)\end{array}$ & $\begin{array}{l}41 \\
(20.5 \%)\end{array}$ & $\begin{array}{l}32 \\
916.0 \%)\end{array}$ & $5(2.5 \%)$ & $200(100.0 \%)$ \\
\hline
\end{tabular}

Table 5 shows the distribution of study subjects based on Norwood Hamilton Scale.

Table 6: Comparison of Hairdex score according to age groups

\begin{tabular}{|c|c|c|c|}
\hline \multicolumn{2}{|l|}{ Hairdex Score } & Mean $( \pm \mathrm{SD})$ & p-value \\
\hline \multirow{6}{*}{ Emotional Score } & $<20$ & $40.6( \pm 2.28)$ & \multirow{6}{*}{$<0.05$} \\
\hline & $21-30$ & $44.05( \pm 4.32)$ & \\
\hline & $31-40$ & $40.98( \pm 6.14)$ & \\
\hline & $41-50$ & $23.72( \pm 10.52)$ & \\
\hline & $>50$ & $17( \pm 0)$ & \\
\hline & Total & $39.14( \pm 9.93)$ & \\
\hline \multirow{4}{*}{ Functional Score } & $<20$ & $25.45( \pm 1.70)$ & \multirow{4}{*}{$<0.05$} \\
\hline & $21-30$ & $31.51( \pm 5.07)$ & \\
\hline & $31-40$ & $31.61( \pm 7.43)$ & \\
\hline & $41-50$ & $17( \pm 7.29)$ & \\
\hline
\end{tabular}




\begin{tabular}{|c|c|c|c|}
\hline & $>50$ & $11( \pm 0)$ & \\
\hline & Total & $28.09( \pm 8.31)$ & \\
\hline \multirow{6}{*}{ Symptom Score } & $<20$ & $15.5( \pm 1.99)$ & \multirow{6}{*}{$<0.05$} \\
\hline & $21-30$ & $14.68( \pm 2.41)$ & \\
\hline & $31-40$ & $15.39( \pm 3.39)$ & \\
\hline & $41-50$ & $15.53( \pm 3.67)$ & \\
\hline & $>50$ & $11.2( \pm 0.45)$ & \\
\hline & Total & $14.96( \pm 2.87)$ & \\
\hline \multirow{6}{*}{ Self Assurance Score } & $<20$ & $12.15( \pm 0.93)$ & \multirow{6}{*}{$<0.05$} \\
\hline & $21-30$ & $14.3( \pm 2.02)$ & \\
\hline & $31-40$ & $16.29( \pm 1.86)$ & \\
\hline & $41-50$ & $17.41( \pm 2.11)$ & \\
\hline & $>50$ & $15.2( \pm 1.64)$ & \\
\hline & Total & $15.02( \pm 2.44)$ & \\
\hline \multirow{6}{*}{ Stigmatization Score } & $<20$ & $35.35( \pm 1.27)$ & \multirow{6}{*}{$<0.05$} \\
\hline & $21-30$ & $33.8( \pm 3.99)$ & \\
\hline & $31-40$ & $28.17( \pm 7.26)$ & \\
\hline & $41-50$ & $18.28( \pm 0)$ & \\
\hline & $>50$ & $16.2( \pm 1.30)$ & \\
\hline & Total & $29.88( \pm 8.02)$ & \\
\hline \multirow{6}{*}{ Total Hairdex Score } & $<20$ & $129.05( \pm 3.53)$ & \multirow{6}{*}{$<0.05$} \\
\hline & $21-30$ & $138.34( \pm 15.4)$ & \\
\hline & $31-40$ & $132.44( \pm 21.95)$ & \\
\hline & $41-50$ & $91.94( \pm 24.19)$ & \\
\hline & $>50$ & $70.6( \pm 1.52)$ & \\
\hline & Total & $127.08( \pm 25.68)$ & \\
\hline
\end{tabular}

Table 7: Hairdex Score in subjects with $\leq 30$ years versus $>30$ years

\begin{tabular}{|c|c|c|c|c|}
\hline Hairdex Score & Age Group (years) & $\mathrm{N}$ & Mean $( \pm \mathrm{SD})$ & p-value \\
\hline \multirow{2}{*}{ Emotional Score } & $\leq 30$ & 122 & $43.5( \pm 4.2)$ & \multirow{2}{*}{$<0.05$} \\
\hline & $>30$ & 78 & $32.4( \pm 12.2)$ & \\
\hline \multirow{2}{*}{ Functional Score } & $\leq 30$ & 122 & $30.5( \pm 5.2)$ & \multirow{2}{*}{$<0.05$} \\
\hline & $>30$ & 78 & $24.3( \pm 10.6)$ & \\
\hline \multirow{2}{*}{ Symptom score } & $\leq 30$ & 122 & $14.8( \pm 2.4)$ & \multirow{2}{*}{0.37} \\
\hline & $>30$ & 78 & $15.2( \pm 3.5)$ & \\
\hline \multirow{2}{*}{ Self Assurance Scare } & $\leq 30$ & 122 & $14.0( \pm 2.0)$ & \multirow{2}{*}{$<0.05$} \\
\hline & $>30$ & 78 & $16.7( \pm 2.0)$ & \\
\hline \multirow{2}{*}{ Stigmatization Score } & $\leq 30$ & 122 & $34.1( \pm 3.7)$ & \multirow{2}{*}{$<0.05$} \\
\hline & $>30$ & 78 & $23.4( \pm 8.6)$ & \\
\hline \multirow{2}{*}{ Total Hairdex Score } & $\leq 30$ & 122 & $136.8( \pm 14.6)$ & \multirow{2}{*}{$<0.05$} \\
\hline & $>30$ & 78 & $111.9( \pm 31.4)$ & \\
\hline
\end{tabular}

Table 6 shows the distribution of study subjects based on Hairdex score. The Quality of Life subscales results showed the younger age group $(<$ 30 years) to be less affected as far as symptoms subscale was considered (table 7). They fared significantly poorly with higher scores than older patients (> 30 years) as far as stigmatization, functioning and emotions were concerned $(\mathrm{p}<$ $0.05)$. However, the younger age group proved to be statistically more self assured $(\mathrm{p}<0.05)$. 


\section{JMSCR Vol||04||Issue||10||Page 12900-12907||October}

Figure 1: Dermatology Life Quality Index (DLQI) according to age groups

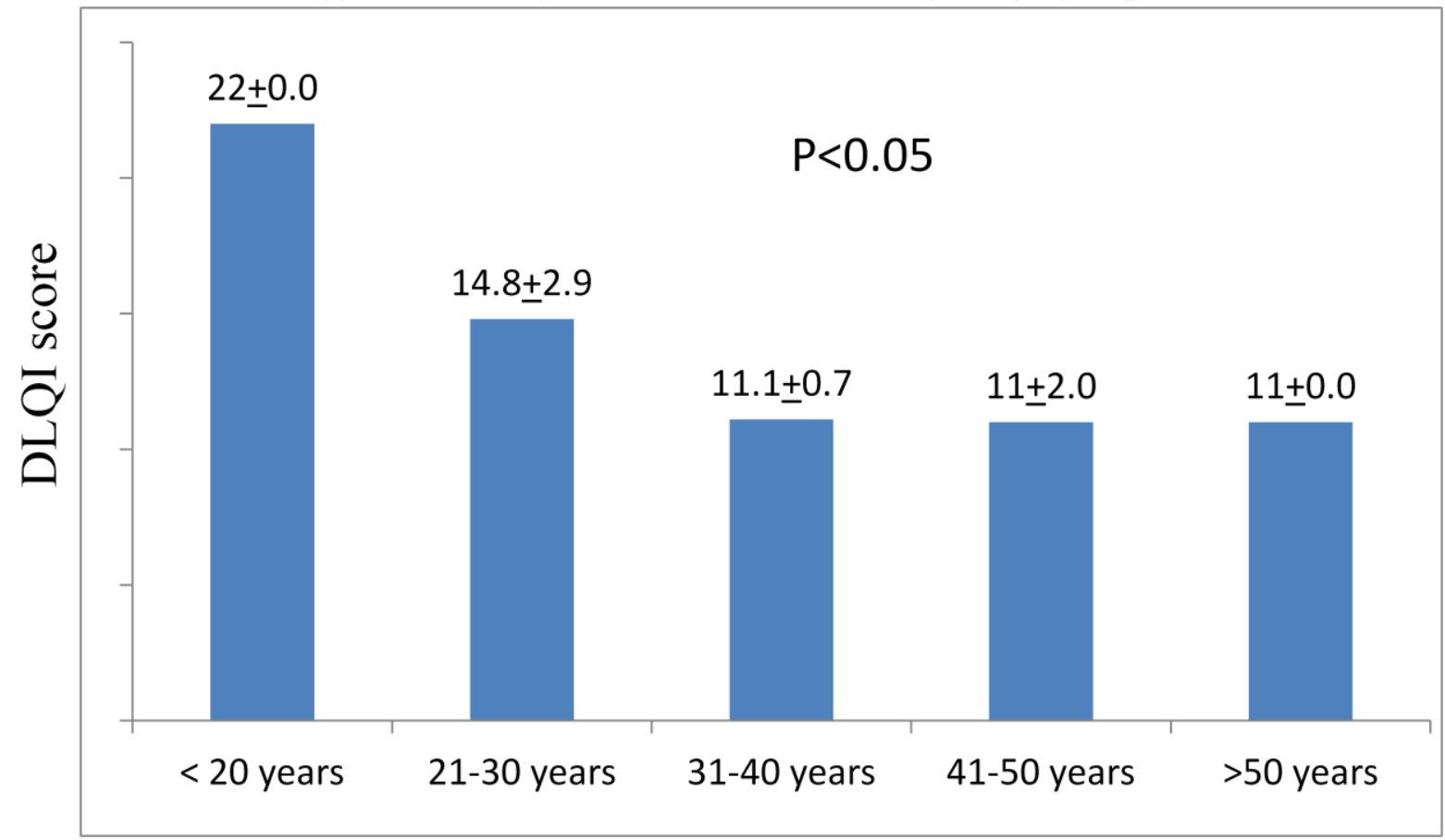

Dermatology Life Quality Index (DLQI) score differed significantly in subjects with different age groups (figure $1 ; \mathrm{p}<0.05$ ) with highest score in subjects less than 20 years of age.

Figure 2: Dermatology Life Quality Index (DLQI) in subjects with $\leq 30$ years versus > 30 years

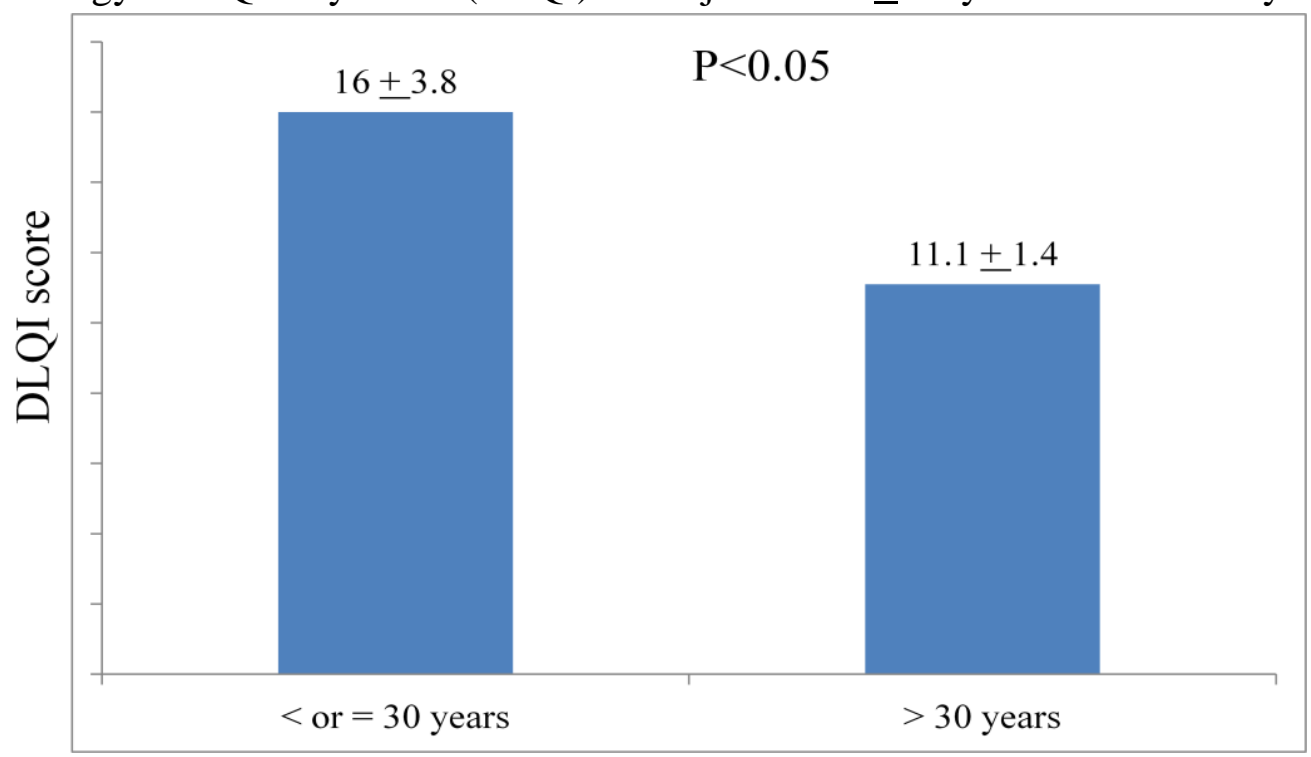

The Mean Dermatology Life Quality Index of younger subjects was significantly higher than older subjects (figure $2 ; \mathrm{p}<0.05$ ).

\section{Discussion}

The present study was evaluated for psychosocial impact and quality of life in males with AGA. Over half of the subjects in present study belonged to 21-30 years of age with mean age of 30.6 years. These findings are important from the point of view that adolescents can also present with AGA.
The incidence gradually increases with age. In an Indian population based study the prevalence of AGA in males aged 30-50 years was 58\%. ${ }^{1}$ Few studies have shown associated lifestyle factors such as smoking with hair loss. ${ }^{6}$

Hair loss in men may be associated with distress, preoccupation, and marked coping efforts. These 
effects are particularly apparent in younger men and those with extensive or early-onset hair loss. ${ }^{7}$ In our study history of stress was present in $66.5 \%$ subjects while acne was present in $39.5 \%$ subjects. However, a study by Brajac in 2003. ${ }^{8}$ was unable to establish causal relationship between alopecia areata with stressful life events. ${ }^{8}$

Positive family history of alopecia was given by $51 \%$ subjects. Twin studies in males indicate that susceptibility, age of onset, pattern and rate of progression of male pattern baldness are under genetic influence. $^{9,} \quad 10$ The lower age-related prevalence of male pattern baldness and higher proportion of men with a Ludwig pattern hair loss among Koreans also confirms the profound influence of genes on susceptibility, age of onset and pattern of hair loss. ${ }^{11}$

The distribution of study subjects based on Norwood Hamilton Scale showed one third of the patients belonged to class III. Younger individuals were found to have less severe grades as compared to older individuals. Regarding the commonest type/grade of presentation (according to the Norwood classification), studies have shown differing results. A large study in the Indian population had type II as the commonest presentation of AGA. ${ }^{12}$ Another study in an Indian population had type II and III as the commonest presentation. ${ }^{13}$ The Chinese study by Wang et al. ${ }^{14}$ had type IV as the commonest type, while the Korean study by Paik et al. ${ }^{15}$ had type III as the commonest type.

Quality-of-life due to hair loss was assessed by administration of the Hairdex scale under five subscales: emotions, functioning, self-assurance, stigmatization and symptoms. ${ }^{4}$ The results showed the younger age group ( $<30$ years) to be less affected as far as symptoms subscale was considered but they fared significantly poorly with higher scores than older patients (> 30 years) as far as stigmatization, functioning and emotions were concerned $(p<0.05)$. However, the younger age group proved to be statistically more self assured $(\mathrm{p}<0.05)$.
The reason for the poor functioning and more stigmatization in the younger patients group can be attributed to certain social factors. In a country like India, great importance is given to physical appearance especially during marriage. People in group A are more likely to be unmarried and bald individuals look older as compared to non bald of similar age group. This could bring emotional instability, poor functioning and increased stigma in these individuals.

Also there is increasing influence of fashion and media which perpetuate this emphasis on physical appearance by portraying stereotypical images of male and female youngsters and adults with full heads of hair. ${ }^{15}$ Feelings of unattractiveness due to a perceived physical deficit or abnormality such as thinning hair can be a source of distress and social dysfunction. This can result in anxiety, depressed mood, isolation, embarrassment, and other social maladjustments.

The younger patients also fared poorly in the subscale entitled 'emotions'. Coupled with the knowledge that an inordinate importance is given to personal appearance in the younger age group covered by our study (15 to 30 years), our findings are in accordance to an older study by Wells (1995), which also notices marked loss of selfesteem and feelings of looking unattractive in younger men. ${ }^{16}$

A study carried out using the same scale on female patients, revealed impaired QoL (i.e. higher scores) in patients with varying degrees of hair loss, even in those whose hair loss is not clearly visible. ${ }^{17}$ Patients experience emotions of annoyance, frustration and humiliation. Also, social life and interaction, especially with the opposite sex is affected. ${ }^{4}$ A study by Alfonso et al . reports that major concerns faced include losing a part of personal attractiveness, becoming bald, getting older, negative effects on social life and feelings of depression. ${ }^{18}$

A change noticed in both groups of patients is the feeling of 'stigmatization' which includes 'feeling like an outsider' and being laughed at by others. ${ }^{4}$ These feelings could be due to perception of peer 
pressure exaggerating the need for social acceptance. Interestingly, a statistically significant better self-assurance scores were found among the younger patient group $(P=0.014)$. The presence of better self-assurance is undoubtedly the result of a generational attitudinal difference between younger and older patients of AGA.

Han $\mathrm{SH}$ et $\mathrm{al}^{19}$ also showed that function and emotion scales are more severly affected in younger age group as compared to older age group.

In a study older patients were more severely afflicted for subscales of functioning, stigmatization and symptoms whereas emotional score was more severely affected in young population. $^{20}$

In our study, older subjects had more severe symptoms. Similar to our findings, Neena et al. ${ }^{20}$ also found symptom score to be more in the older age group as compared with younger individuals.

The Mean Dermatology Life Quality Index of younger subjects was higher than older subjects indicating quality of life of younger group to be significantly less affected compared to older subjects. The finding can be attributed to the duration and severity of condition.

Our results correlate with a published study which showed higher scores in individuals with longer duration of condition. ${ }^{21}$ Williamson $\mathrm{D}$ et al. recruited subjects from an alopecia support group, and were assessed using the Dermatology Life Quality Index (DLQI). The mean DLQI score confirms significant disability when compared with the mean DLQI score of normal controls (0.5), reported in a previous study. ${ }^{22}$ Overall results showed that quality of life of younger group to be less affected compared to older subjects $(\mathrm{p}<0.05)$.

The study provides valuable insight into psychological and aspects related to AGA. However, our study observations should be interpreted in light of following limitations. The major limitation of our study was small sample size. All the patients were from a single tertiary academic centre our results might not be generalized to other hospitals or community people.

\section{Conclusion}

Positive Family history plays a role and appears to be associated with age of onset of hair loss and patients with positive family history seem to present at young age. Younger patients seem to be more stigmatized, have poor functioning and emotions stability, but they had more self assuredness. Younger patients seem to retain better Quality of Life in spite of AGA. The poor symptom score and quality of life in elderly can be attributed to the increased duration and severity of their condition.

\section{References}

1. Krupa Shankar DS, Chakravarthi M, Shilpakar R. Male Androgenetic Alopecia: Population-Based Study in 1,005 Subjects. Int J Trichology. 2009; 1: 131-133.

2. Hunt N, McHale S. The psychological impact of alopecia. BMJ. 2005 Oct 22; 331(7522): 951-953.

3. Kuppuswamy B. Manual of Socioeconomic Status (Urban). $1^{\text {st }}$ ed. Delhi: Manasayan; 1981. p. 66-72.

4. Fischer TW, Schmidt S, Strauss B, Elsner P. Hairdex: An instrument to assess disease-specific quality of life in alopecia patients. Hautarzt. 2001;52:219-27

5. Finlay AY, Khan GK. Dermatology Life Quality Index (DLQI)--a simple practical measure for routine clinical use. Clin Exp Dermatol 1994;19:210-6

6. Trüeb RM. Association between smoking and hair loss: Another opportunity for health education against smoking? Dermatology 2003;206:189-91.

7. Cash TF. The psychological effects of androgenetic alopecia in men. J Am Acad Dermatol. 1992;26:926-931.

8. Brajac I, Tkalcic M, Dragojević DM, Gruber F. Roles of stress, stress perception and trait-anxiety in the onset and course of 
alopecia areata. J Dermatol 2003;30:8718.

9. Stough DB, Rao NA, Kaufman KD, Mitchell C. Finasteride improves male patternhair loss in a randomized study in identical twins. Eur J Dermatol 2002; 12:32-7.

10. Nyholt D, Gillespie N, Heath A. Genetic basis of male pattern balding. J Invest Dermatol 2003; 121: 1561-4.

11. Paik JH, Yoon JB, Sim WY, Kim BS, Kim NI. The prevalence and types of androgeneticalopecia in Korean men and women.Br J Dermatol 2001; 145: 95-9.

12. Grover S. A study of patterns of androgenetic alopecia in men: An Indian perspective. Br J Dermatol 2005;152:5724.

13. Sehgal VN, Kak R, Aggarwal A, Srivastava G, Rajput P. Malepattern androgenetic alopecia in an Indian context: A perspectivestudy. J EurAcad Dermatol Venereol 2007;21:473-9.

14. Wang TL, Zhou C, Shen YW, Wang XY, Ding XL, Tian S, et al. Prevalence of androgenetic alopecia in China: A community-based study in six cities. $\mathrm{Br} \mathrm{J}$ Dermatol 2010;162:843-7

15. Price VH. Androgenetic alopecia in adolescents. Cutis 2003;71: 115-121.

16. Wells PA, Willmoth T, Russell RJ. Does fortune favour the bald? Psychological correlates of hair loss in males. $\mathrm{Br} J$ Psychol 1995;86:337-44.

17. Schmidt S, Fischer TW, Chren MM, Strauss BM, Elsner P. Strategies of coping and quality of life in women with alopecia. Br J Dermatol 2001;144:1038-43.

18. Alfonso M, Richter-Appelt H, Tosti A, Viera MS, García M. The psychosocial impact of hair loss among men: A multinational European study. Curr Med Res Opin 2005;21:1829-36.
19. Han SH, Byun JW, Lee WS, Kang H, Kye YC, Kim KH, et al. Quality of life assessment in male patients with androgenetic alopecia: result of a prospective, multicenter study. Annals of dermatology 24.3 (2012): 311-318

20. Sawant N, Chikhalkar S, Mehta V, Ravi M, Madke B, Khopkar U., et al. Androgenetic alopecia: Quality-of-life and associated lifestyle patterns. International journal of trichology 2.2 (2010): 81.

21. Tahir K, Aman S, Naddem M, Kazmi AH. Quality of life in patients with androgenetic alopecia. Annals of King Edward Medical University 2013;19:150154

22. Williamson, D. Gonzalez M, Finlay AY. The effect of hair loss on quality of life. Journal of the European Academy of Dermatology and Venereology 2001;15;2: 137-39. 